\title{
Leukotrienes as Modifiers of Preclinical Atherosclerosis?
}

\author{
Graziano Riccioni' ${ }^{1}$ and Magnus Bäck ${ }^{2}$ \\ ${ }^{1}$ Cardiology Unit, San Camillo de Lellis Hospital, Manfredonia, Foggia, Italy \\ ${ }^{2}$ Department of Cardiology and Center for Molecular Medicine, Karolinska University Hospital, Stockholm, Sweden
}

Correspondence should be addressed to Graziano Riccioni, griccioni@hotmail.com

Received 7 July 2011; Accepted 15 December 2011

Academic Editor: C. N. Serhan

Copyright (C 2012 G. Riccioni and M. Bäck. This is an open access article distributed under the Creative Commons Attribution License, which permits unrestricted use, distribution, and reproduction in any medium, provided the original work is properly cited.

Preclinical atherosclerosis represents a crucial period associated with several pathophysiological reactions in the vascular wall. Failure to diagnose preclinical atherosclerosis at this stage misses a major opportunity to prevent the long-term consequences of this disease. Surrogate biological and structural vascular markers are available to determine the presence and the extension of preclinical vascular injury in the general population. Examples of surrogate markers are carotid intima media thickness and biomarkers including high-sensitivity C-reactive protein, cell adhesion molecules and matrix metalloproteinases, and leukotrienes. Recently, leukotrienes have been implicated as mediators, biomarkers, and possible therapeutic targets in the context of subclinical atherosclerosis. The aim of this short paper is to focus on the relation between preclinical atherosclerosis and leukotrienes, with particular attention to the recent development on the use of leukotriene modifiers in the treatment of atherosclerosis.

\section{Introduction}

Atherosclerosis, a progressive disease of large arteries with a long asymptomatic phase, accounts for much of the global epidemic of cardiovascular disease (CVD). During the past decades, the concept of atherosclerosis has become refined with a focus on the inflammatory nature of the atherosclerotic lesion [1].

Inflammation in atherosclerosis involves alteration of the endothelial monolayer, which in the normal state resist prolonged contact with leukocytes. Risk factors such as elevated levels of low-density lipoprotein cholesterol (LDL-C) lead to endothelial changes [2]. The altered endothelium expresses a series of adhesion molecules, such as vascular cell adhesion molecule1 (VCAM-1) and P-selectin, which participate in the initiation of atherosclerosis [3]. A number of chemoattractants in addition drive the migration of adhered leukocytes into the arterial intima where the atherosclerotic lesions form. This migration result from the action of chemoattractants, such as monocyte chemoattractant protein 1 (MCP-1) and leukotriene $\mathrm{B}_{4}$. Atherosclerotic disease progression can lead eventually to acute cardiovascular events, such as acute myocardial infarction (AMI), unstable angina (UA) pectoris, sudden cardiac death, or stroke [4]. While the disease is still in a subclinical stage, however, the presence of atherosclerosis can be identified by several methods, including coronary angiography, intravascular ultrasonography (IVUS), B-mode ultrasonography, computed tomography (CT) scan, and magnetic resonance imaging (MRI). In addition, vascular biomarkers such as high-sensitivity C-reactive protein (hsCRP) and cell adhesion molecules have proven to be useful to predict subclinical atherosclerosis. Recently, leukotrienes (LTs) have been implicated as mediators, biomarkers, and possible therapeutic targets in the context of subclinical atherosclerosis.

\section{LTs: Definition, Synthesis, and Function}

LTs are arachidonic acid (AA) derived lipid mediators of inflammation. The initial step in the formation of LTs is catalyzed by 5-lipoxygenase (5-LOX) in conjunction with its five lipoxygenase activating protein (FLAP) $[5,6]$. Subsequently, LTC $_{4}$ synthase leads to the formation of the family of cysteinyl leukotrienes (CysLTs) including leukotriene $\mathrm{C}_{4}\left(\mathrm{LTC}_{4}\right)$, leukotriene $\mathrm{D}_{4}\left(\mathrm{LTD}_{4}\right)$, and leukotriene $\mathrm{E}_{4}\left(\mathrm{LTE}_{4}\right)$, whereas the noncysteine-containing dihydroxyleukotriene $\mathrm{B}_{4}\left(\mathrm{LTB}_{4}\right)$ is formed through the action of the enzyme $\mathrm{LTA}_{4}$ hydrolase 
[6]. LTs are mainly produced by macrophages infiltrating atherosclerotic lesions and act in an autocrine/paracrine manner within the vascular wall. For example, $\mathrm{LTB}_{4}$ is a potent chemoattractant for monocytes, neutrophil granulocytes, and $\mathrm{T}$ lymphocytes, that promotes leukocyte adhesion to vascular endothelium, augments vascular permeability, and promotes vascular smooth cells (VSMCs) proliferation and migration $[7,8]$. The two receptors for $\mathrm{LTB}_{4}$ are termed $\mathrm{BLT}_{1}$ and $\mathrm{BLT}_{2}$. The $\mathrm{BLT}_{1}$ receptor is the highaffinity receptor specific for $\mathrm{LTB}_{4}$ expressed in leukocytes, vascular smooth muscle cells, and endothelial cells and mediates chemotaxis [9]; $\mathrm{BLT}_{2}$ is a pharmacologically distinct receptor ubiquitously expressed and displays low affinity for $\mathrm{LTB}_{4}$ and also binds other agonists [10]. For example, the thromboxane synthase metabolite 12-L-hydroxy-5,8,10heptadecatrienoic acid (12-HHT) has been identified as a more potent ligand for $\mathrm{BLT}_{2}$ than $\mathrm{LTB}_{4}$, although the specific role of 12-HHT activation of leukotriene receptors in CVD has not been extensively explored [11].

CysLTs $\left(\mathrm{LTC}_{4}, \mathrm{LTD}_{4}\right.$, and $\left.\mathrm{LTE}_{4}\right)$ are potent vasoconstrictors and also enhance vascular permeability [12]. In addition, in vivo studies have shown that CysLTs, reduce coronary blood flow, decrease myocardial contractility, and regulate blood pressure [13]. CysLTs also stimulate proliferation of arterial smooth muscle cells and promote P-selectin surface expression, von Willebrand factor secretion, and plateletactivating factor (PAF) synthesis in cultured endothelial cells (EC) [14]. CysLTs exert their biological effects by activating specific receptors termed $\mathrm{CysLT}_{1}$ and $\mathrm{CysLT}_{2}$, of which the $\mathrm{CysLT}_{1}$ receptor is blocked by the antileukotrienes used clinically in the treatment of asthma [10].

\section{Endothelial Dysfunction: A Preclinical Atherosclerosis Phase}

Endothelial injury may be one starting point for atherosclerosis. Such injury can result from a variety of factors, including increased local shear forces from hypertension, elevated plasma concentrations of LDL-C, chemical toxins in for example cigarette smoke, and diabetes mellitus. These factors decrease (EC) production of nitric oxide (NO), thereby impairing vasodilatory capacity, normal barrier, and protective functions of the vascular endothelium. Dysfunctional EC in addition upregulate, a number of adhesion molecules, which promote the binding of circulating monocytes to vascular EC [15]. Whereas EC in nonatherosclerotic arteries are devoid of BLT receptors, the endothelium lining human carotid atherosclerotic lesions have been demonstrated to be positive for the $\mathrm{BLT}_{1}$ receptor [16]. In line with these findings, human umbilical vein endothelial cells (HUVECs) exhibit $\mathrm{BLT}_{1}$ upregulation after stimulation with the proinflammatory cytokines LPS and IL-1 $\beta$ in vitro [17]. In addition, in vitro studies have demonstrated a $\mathrm{LTB}_{4}$-induced release of vasoactive factors via BLT receptor activation [18, 19]. These reports provide evidence for a role of $\mathrm{LTB}_{4}$ in regulating endothelial function.

The CysLT 2 receptor appears to be the dominating CysLT receptor in normal EC [20], but endothelial $\mathrm{CysLT}_{1}$ receptor expression can be induced after prolonged exposure to IL$1 \beta$ [21]. Furthermore, studies of human brain tissue have revealed $\mathrm{CysLT}_{1}$ receptor immunostaining in microvascular EC [22]. Studies in isolated vessels have associated CysLT receptor signaling with the release of contractile factors, whereas the $\mathrm{CysLT}_{2}$ receptor appears preferentially coupled to the release of NO [23]. Furthermore, $\mathrm{LTC}_{4}$ and $\mathrm{LTD}_{4}$ upregulate endothelial P-selectin expression [24] and increase the transcription of the CXC chemokines MIP2- $\alpha$ [25] and IL-8 [26].

\section{Immunoactivation: A Pivotal Step in Atherosclerosis Progression}

The dysfunctional endothelium will hence promote the recruitment of immune cells. Once attached, monocytes will be exposed to several chemokines that promote the transmigration of bound monocytes into the subendothelial space, and to colony stimulating factors, that promotes the differentiation of monocytes into macrophages. In addition to the stimulation of endothelial adhesion molecules discussed above, the direct chemotactic activity of $\mathrm{LTB}_{4}$ may also participate in monocyte/macrophage accumulation during atherogenesis.

Macrophages expressing scavenger receptors (SRA, CD36) will bind and promote the internalization of oxidized LDL $\left(\mathrm{LDL}_{\mathrm{ox}}\right)$ and a broad range of other particles and cell fragments [15]. As the macrophages progressively accumulate more and more cholesterol, cytosolic lipid droplets form, and the macrophage become a lipid-laden foam cell. Although the exact role of LTs in oxidized LDL uptake remains to be established, the enhanced CD-36 expression and increased uptake of $\mathrm{LDL}_{\mathrm{ox}}$ induced by 4-hydroxynonenal are blunted when 5-LO activity is inhibited by a pharmacological inhibitor, and in macrophages derived from 5LO-deficient mice [27]. Furthermore, $\mathrm{LDL}_{\mathrm{ox}}$ upregulates FLAP expression in monocytic cell lines [28], suggesting also an enhancing function of $\mathrm{LDL}_{\mathrm{ox}}$ on leukotriene-driven inflammation in atherosclerosis. In addition to monocytes, T-lymphocytes infiltrate the developing lesion site from both the intimal and adventitial aspects of the vessel wall $[29,30]$. $\mathrm{LTB}_{4}$ is a potent chemoattractant for T-lymphocytes and may also be a key mediator in a lymphocyte-monocyte cross-talk enhancing inflammatory circuits in atherosclerosis [31]. In addition, $\mathrm{LTB}_{4}$ stimulates the release of matrix metalloproteinases (MMPs) from T-lymphocytes in vitro [32]. The MMP family of enzymes is involved in arterial wall extracellular matrix degradation and remodeling [33]. In addition to stimulating T-lymphocyte MMPs, LTs also induce MMP release from neutrophil granulocytes [34], monocytes [35], and vascular smooth muscle cells [36, 37].

\section{Biomarkers of Subclinical Atherosclerosis}

Dysfunction of the endothelium may be considered as an early and potentially reversible step in the process of atherogenesis, and numerous methods have been developed to assess endothelial status and large artery stiffness [38]. 
Several biochemical markers have been identified, which correlate with coronary artery disease (CAD) and conventional CVD risk factors [39]. Such biomarkers include, $\mathrm{LDL}_{\mathrm{ox}}$, hsCRP, endothelial progenitor cells (EPC), prothrombotic factors such as von Willebrand factor (VWF), and inflammatory markers including tumor necrosis factor- $\alpha$ (TNF- $\alpha$ ), IL-6, and intracellular adhesion molecule-1 (ICAM-1) $[40,41]$, as well as different members of the MMP family [33].

\section{LTs and Subclinical Atherosclerosis: Genetic Evidence}

The first suggestion for the involvement of the LTs pathway in subclinical atherosclerosis was provided by Dwyer and coworkers, reporting an association of the number of Sp1/Egr1 motifs within the 5-LO promoter sequence with an increased carotid intima-media thickness [42]. In the latter study, carriers of the variant genotypes in addition exhibited 2-fold higher levels of hs-CRP. Genetic variations in other constituents of the LTs pathway have also been demonstrated to correlate with measures of subclinical atherosclerosis. For example, a SNP within the $\mathrm{LTC}_{4}$ synthase promoter correlated with carotid intima-media thickness and coronary calcium [43]. Finally, the genetic association of the LTs pathway with atherosclerosis is also supported by studies of CVD outcomes, in which variations in the genes encoding FLAP, LTC $_{4}$ synthase, and $\mathrm{LTA}_{4}$ hydrolase [44] have been associated with a higher prevalence of $\mathrm{MI}$ and/or stroke.

\section{LTs and Atherosclerosis: Experimental Evidence}

Targeting the 5-LO enzyme in animal models of atherosclerosis have generated contradictory results $[45,46]$. However, pharmacological inhibition of FLAP in different atherosclerosis prone mice has shown reduced lesion size [31, 47, 48].

$\mathrm{LTB}_{4}$ is one of the most potent chemoattractants formed within the atherosclerotic lesion, and several leukocyte subpopulations with importance for atherosclerosis development have been shown to be activated by $\mathrm{LTB}_{4}$ [49]. In human atherosclerotic lesions, macrophages stain positive for both BLT receptor subtypes [16], and in vitro studies have supported a role for both the high-affinity BLT $_{1}$ receptor and the low-affinity $\mathrm{BLT}_{2}$ receptor in macrophage recruitment to atherosclerotic lesions $[16,34]$. Furthermore, BLT receptor expression on T-lymphocytes may play a key role in the immunological reactions within the atherosclerotic lesion [31]. In addition to macrophages and T-lymphocytes, also granulocytes express BLT receptors [49] and, although incompletely explored in atherosclerosis, $\mathrm{LTB}_{4}$ was recently demonstrated as a key mediator of neutrophil chemotaxis and activation in human aortic abdominal aneurysms [34].

In addition to leukocyte activation, $\mathrm{LTB}_{4}$ also induces effects on structural components of the vascular wall $[16,36$, $50,51]$. In addition to endothelium-dependent vasomotor responses discussed above, $\mathrm{LTB}_{4}$ also induces contractions of some vascular segments lacking a functional endothelium
[52], and BLT receptor expression was subsequently demonstrated on VSMC $[16,53]$. Furthermore, experimental models targeting the $\mathrm{BLT}_{1}$ receptor have indicated the importance of $\mathrm{LTB}_{4}$-induced VSMC migration and proliferation in the development of atherosclerosis [16, 53]. Finally, BLT receptor antagonism reduces the intimal hyperplasia in response to balloon angioplasty with stent implantation in hypercholesterolemic rabbits [36], suggesting a potential use of antileukotrienes in the prevention of restenosis following coronary percutaneous interventions. Likewise, either pharmacological $[54,55]$ or genetic $[55,56]$ targeting of the BLT receptor reduces atherosclerotic lesion size in hyperlipidemic mice.

CysLTs induce contraction of atherosclerotic human coronary arteries [57]. Recently, the CysLT pathway was associated with aortic stenosis, a vascular inflammation which shares several characteristics with atherosclerosis [58]. In this context, $\mathrm{LTC}_{4}$ stimulation of valvular myofibroblasts increased reactive oxygen species production and induced calcification. In addition, the local expression levels of 5LO correlated with the severity of valvular disease, suggesting that the role of the leukotriene pathway in CVD may extend beyond atherosclerosis.

Pharmacological targeting of the CysLT 1 receptor retards atherosclerotic lesion growth in hyperlipidemic mice $[59,60]$ and reduces the intimal hyperplasia in response to vascular injury [61].

\section{LTs as Biomarkers of Atherosclerosis and CV Risk}

Ex vivo incubations of human atherosclerotic lesions have shown an increased release of both CysLTs [62] and LTB4 [63] compared with healthy human vessels. Brezinski et al. [64] detected an increased local LTs production during coronary interventions, and a systemic increase in $\mathrm{LTB}_{4}$ formation has been detected through ex vivo stimulation of leukocytes derived from patients with a history of AMI [65]. The latter approach was recently used in a study of subjects with obstructive sleep apnea [66], which demonstrated correlations of $\mathrm{LTB}_{4}$ concentrations with measures of carotid artery remodelling. Patients with obstructive sleep apnoea in addition exhibit urinary excretion of $\mathrm{LTE}_{4}$, which is associated with the severity of sleep apnoea and obesity [67]. Since both sleep apnoea and obesity are established CVD risk factors, the latter findings warrant further investigation of the potential of LTs as biomarkers of atherosclerosis and CVD risk. Finally, oral concentrations of LTs may represent another interesting approach for the evaluation of LTs as CVD biomarkers [68]. For example, subjects with high concentrations of CysLTs in gingival crevicular fluid have an increased carotid artery wall thickness, regardless of their dental status [69].

\section{LT Modifiers and Atherosclerosis: The Clinical Experience}

Inflammation plays an important role in atherosclerosis process. In particular, many enzymes associated with the 
5LO pathway are abundantly expressed in arterial walls of patients afflicted with various lesion stages of atherosclerosis of the aorta and of coronary arteries [41]. In a randomized, placebo-controlled trial, Hakonarson et al. [70] demonstrated that an inhibitor of FLAP (DG-031) led to significant and dose-dependent suppression of plasmatic biomarkers that are associated with increased risk of AMI events. The authors randomized 191 patients, who carry atrisk variants in the arachidonate 5-lipoxygenase-activating protein (ALOX5AP) gene $(87 \%)$ or in the leukotriene A4 hydrolase gene $(13 \%)$, to receive $250 \mathrm{mg} / \mathrm{d}$ of DG-031, $500 \mathrm{mg} / \mathrm{d}$ of DG-031, $750 \mathrm{mg} / \mathrm{d}$ of DG-031, or placebo for 4 weeks. In patients with specific at-risk variants of 2 genes in the leukotriene pathway, DG-031 led to significant and dose-dependent suppression of hs-CRP that is associated with increased risk of AMI events. Even Allayee et al. [71] provided evidence that montelukast and low-dose theophylline decrease certain inflammatory and lipid CVD risk factors. In this study, the authors randomized 133 patients with moderate-to-severe asthma to receive either montelukast $(10 \mathrm{mg} / \mathrm{d})$, theophylline $(300 \mathrm{mg} / \mathrm{d})$, or placebo for 6 months. Asthmatic patients receiving montelukast and, to some extent, low-dose theophylline have lower levels of CVD-associated inflammatory biomarkers (hs-CRP, IL-6) and lipid levels.

In acute coronary syndrome (ACS), a potent 5LO inhibitor (VIA-2291) reduces leukotriene production as demonstrated by Tardif et al. [72] in a double blind trial with placebo. In this study, 191 patients were randomly assigned 3 weeks after an ACS to receive 25, 50, or $100 \mathrm{mg}$ VIA2291 or placebo daily for 12 weeks. A significant reduction of urine leukotriene $\mathrm{LTE}_{4}$ was obtained in all dose groups with the absence of serious adverse events. In this study, a subset of patients $(n=60)$ underwent a 64 -slice coronary CT examination at baseline continued on study medication for a total of 24 weeks and underwent a repeat scan. A significant reduction in noncalcified plaque volume at 24 weeks versus placebo was observed in VIA-2291 - treated groups in the 34 of these 60 patients in whom this end point was analyzable.

In a registry-based nation-wide Swedish cohort of almost 7 million subjects followed for 3.5 years, montelukast use was associated with a borderline significant protective effect on recurrent stroke [73]. Based on significant interactions, a subgroup analysis revealed that montelukast use was associated with a significantly reduced risk of recurrent stroke in subjects not receiving angiotensin-modifying drugs. In the same study, a stratified analysis revealed that montelukast use significantly reduced the risk of recurrent myocardial infarction in males [73]. These results provide a first indication for beneficial effects of the CysLT1 receptor antagonist montelukast in the secondary prevention of stroke and myocardial infarction.

\section{Conclusions}

The inflammatory process of atherosclerosis is associated with several pathophysiological reactions characterized by the production of LTs, which induce proinflammatory signaling through activation of specific BLT and CysLT receptors.
CysLTs and $\mathrm{LTB}_{4}$ exert a range of the proinflammatory effects and have proved to be important mediators in inflammatory conditions such as preclinical atherosclerosis. For this reason, leukotriene synthesis inhibitors and leukotriene receptor antagonists have been suggested to induce beneficial effects at preclinical stages of the atherosclerotic process.

Further experimental and clinical studies are needed to determine the potential therapeutic strategies targeting the LT pathway in CVD for to increase a potential use of these drugs in cardiovascular and cerebrovascular diseases $[74,75]$. The exact role of LTRAs in disease management is still evolving. Large-scale, controlled trials are needed to determine the effectiveness and the safety deriving from the use of LTRAs in CVD.

\section{References}

[1] P. Libby, "Inflammation in atherosclerosis," Nature, vol. 420, no. 6917, pp. 868-874, 2002.

[2] B. J. Arsenault, S. M. Boekholdt, and J. J. P. Kastelein, "Lipid parameters for measuring risk of cardiovascular disease," Nature Reviews Cardiology, vol. 8, no. 4, pp. 197-206, 2011.

[3] Y. Huo and L. Xia, "P-selectin glycoprotein ligand-1 plays a crucial role in the selective recruitment of leukocytes into the atherosclerotic arterial wall," Trends in Cardiovascular Medicine, vol. 19, no. 4, pp. 140-145, 2009.

[4] M. Miller, "An emerging paradigm in atherosclerosis: focus on subclinical disease," Postgraduate Medicine, vol. 121, no. 2, pp. 49-59, 2009.

[5] C. D. Funk, "Leukotriene inflammatory mediators meet their match," Science Translational Medicine, vol. 3, no. 66, article 66ps3, 2011.

[6] A. P. Sampson, "FLAP inhibitors for the treatment of inflammatory diseases," Current Opinion in Investigational Drugs, vol. 10, no. 11, pp. 1163-1172, 2009.

[7] D. Keppler, "Leukotrienes: biosynthesis, transport, inactivation, and analysis," Reviews of Physiology Biochemistry and Pharmacology, vol. 121, pp. 1-30, 1992.

[8] B. Samuelsson, "The discovery of the leukotrienes," American Journal of Respiratory and Critical Care Medicine, vol. 161, no. 2, pp. S2-S6, 2000.

[9] B. Samuelsson, S. E. Dahlen, and J. A. Lindgren, "Leukotrienes and lipoxins: structures, biosynthesis, and biological effects," Science, vol. 237, no. 4819, pp. 1171-1176, 1987.

[10] M. Bäck, S. E. Dahlen, J. M. Drazen et al., "International Union of Basic and Clinical Pharmacology. LXXXIV: leukotriene receptor nomenclature, distribution, and pathophysiological functions," Pharmacological Reviews, vol. 63, no. 3, pp. 539584, 2011.

[11] T. Okuno, Y. Iizuka, H. Okazaki, T. Yokomizo, R. Taguchi, and T. Shimizu, "12(S)-hydroxyheptadeca-5Z, 8E, 10E-trienoic acid is a natural ligand for leukotriene B4 receptor 2," Journal of Experimental Medicine, vol. 205, no. 4, pp. 759-766, 2008.

[12] C. D. Funk, "Prostaglandins and leukotrienes: advances in eicosanoid biology," Science, vol. 294, no. 5548, pp. 1871-1875, 2001.

[13] C. Vigorito, A. Giordano, R. Cirillo, A. Genovese, F. Rengo, and G. Marone, "Metabolic and hemodynamic effects of peptide leukotriene C4 and D4 in man," International Journal of Clinical and Laboratory Research, vol. 27, no. 3, pp. 178-184, 1997. 
[14] V. Capra, M. D. Thompson, A. Sala, D. E. Cole, G. Folco, and G. E. Rovati, "Cysteinyl-leukotrienes and their receptors in asthma and other inflammatory diseases: critical update and emerging trends," Medicinal Research Reviews, vol. 27, no. 4, pp. 469-527, 2007.

[15] S. Chrissobolis, A. A. Miller, G. R. Drummond, B. K. KempHarper, and C. G. Sobey, "Oxidative stress and endothelial dysfunction in cerebrovascular disease," Frontiers in Bioscience, vol. 16, no. 5, pp. 1733-1745, 2011.

[16] M. Bäck, D. X. Bu, R. Bränström, Y. Sheikine, Z. Q. Yan, and G. K. Hansson, "Leukotriene B4 signaling through NF- $\kappa$ Bdependent BLT 1 receptors on vascular smooth muscle cells in atherosclerosis and intimal hyperplasia," Proceedings of the National Academy of Sciences of the United States of America, vol. 102, no. 48, pp. 17501-17506, 2005.

[17] H. Qiu, A.-S. Johansson, M. Sjöström et al., "Differential induction of BLT receptor expression on human endothelial cells by lipopolysacharide, cytokines, and leukotriene $\mathrm{B}_{4}$," Proceedings of the National Academy of Sciences of the United States of America, vol. 103, no. 18, pp. 6913-6918, 2006.

[18] M. Bäck, H. Qiu, J. Z. Haeggström, and K. Sakata, "Leukotriene $\mathrm{B}_{4}$ is an indirectly acting vasoconstrictor in guinea pig aorta via an inducible type of BLT receptor," American Journal of Physiology, vol. 287, no. 1 56-1, pp. H419-H424, 2004.

[19] M. Bäck, K. Sakata, H. Qiu, J. Z. Haeggström, and S. E. Dahlén, "Endothelium-dependent vascular responses induced by leukotriene $\mathrm{B}_{4}$," Prostaglandins and Other Lipid Mediators, vol. 83, no. 3, pp. 209-212, 2007.

[20] H. Mita, M. Hasegawa, H. Saito, and K. Akiyama, "Levels of cysteinyl leukotriene receptor mrna in human peripheral leucocytes: significantly higher expression of cysteinyl leukotriene receptor 2 mrna in eosinophils," Clinical and Experimental Allergy, vol. 31, no. 11, pp. 1714-1723, 2001.

[21] K. Gronert, T. Martinsson-Niskanen, S. Ravasi, N. Chiang, and C. N. Serhan, "Selectivity of recombinant human leukotriene $\mathrm{D}_{4}$, leukotriene $\mathrm{B}_{4}$, and lipoxin $\mathrm{A}_{4}$ receptors with aspirintriggered 15-epi-LXA ${ }_{4}$ and regulation of vascular and inflammatory responses," American Journal of Pathology, vol. 158, no. 1, pp. 3-9, 2001.

[22] W. P. Zhang, H. Hu, L. Zhang et al., "Expression of cysteinyl leukotriene receptor 1 in human traumatic brain injury and brain tumors," Neuroscience Letters, vol. 363, no. 3, pp. 247251, 2004.

[23] M. Bäck, "Leukotriene receptors: crucial components in vascular inflammation," TheScientificWorldJournal, vol. 7, pp. 1422-1439, 2007.

[24] K. E. Pedersen, B. S. Bochner, and B. J. Undem, "Cysteinyl leukotrienes induce P-selectin expression in human endothelial cells via a non-CysLT1 receptor-mediated mechanism," Journal of Pharmacology and Experimental Therapeutics, vol. 281, no. 2, pp. 655-662, 1997.

[25] L. Zhao, M. P. W. Moos, R. Gräbner et al., "The 5-lipoxygenase pathway promotes pathogenesis of hyperlipidemia-dependent aortic aneurysm," Nature Medicine, vol. 10, no. 9, pp. 966-973, 2004.

[26] B. Uzonyi, K. Lötzer, S. Jahn et al., "Cysteinyl leukotriene 2 receptor and protease-activated receptor 1 activate strongly correlated early genes in human endothelial cells," Proceedings of the National Academy of Sciences of the United States of America, vol. 103, no. 16, pp. 6326-6331, 2006.

[27] M. R. Yun, D. S. Im, S. J. Lee et al., "4-hydroxynonenal enhances CD36 expression on murine macrophages via p38 MAPK-mediated activation of 5-lipoxygenase," Free Radical Biology and Medicine, vol. 46, no. 5, pp. 692-698, 2009.
[28] A. Fair and K. A. Pritchard Jr., "Oxidized low density lipoprotein increases U937 cell 5-lipoxygenase activity: induction of 5-lipoxygenase activating protein," Biochemical and Biophysical Research Communications, vol. 201, no. 2, pp. 1014-1020, 1994.

[29] R. M. Rao, L. Yang, G. Garcia-Cardena, and F. W. Luscinskas, "Endothelial-dependent mechanisms of leukocyte recruitment to the vascular wall," Circulation Research, vol. 101, no. 3, pp. 234-247, 2007.

[30] G. K. Hansson, "Mechanisms of disease: inflammation, atherosclerosis, and coronary artery disease," New England Journal of Medicine, vol. 352, no. 16, pp. 1685-1695, 2005.

[31] M. Bäck, A. Sultan, O. Ovchinnikova, and G. K. Hansson, "5Lipoxygenase-activating protein: a potential link between innate and adaptive immunity in atherosclerosis and adipose tissue inflammation," Circulation Research, vol. 100, no. 7, pp. 946-949, 2007.

[32] D. Leppert, S. L. Hauser, J. L. Kishiyama, S. An, L. Zeng, and E. J. Goetzl, "Stimulation of matrix metalloproteinase-dependent migration of T cells by eicosanoids," FASEB Journal, vol. 9, no. 14, pp. 1473-1481, 1995.

[33] M. Bäck, D. F. J. Ketelhuth, and S. Agewall, "Matrix metalloproteinases in atherothrombosis," Progress in Cardiovascular Diseases, vol. 52, no. 5, pp. 410-428, 2010.

[34] X. Houard, V. Ollivier, L. Louedec, J. B. Michel, and M. Bäck, "Differential inflammatory activity across human abdominal aortic aneurysms reveals neutrophil-derived leukotriene $B_{4}$ as a major chemotactic factor released from the intraluminal thrombus," FASEB Journal, vol. 23, no. 5, pp. 1376-1383, 2009.

[35] D. F. J. Ketelhuth and M. Bäck, "The role of matrix metalloproteinases in atherothrombosis," Current Atherosclerosis Reports, vol. 13, no. 2, pp. 162-169, 2011.

[36] H. Hlawaty, M. P. Jacob, L. Louedec et al., "Leukotriene receptor antagonism and the prevention of extracellular matrix degradation during atherosclerosis and in-stent stenosis," Arteriosclerosis, Thrombosis, and Vascular Biology, vol. 29, no. 4, pp. 518-524, 2009.

[37] K. W. Seo, S. J. Lee, C. E. Kim et al., "Participation of 5-lipoxygenase-derived LTB4 in 4-hydroxynonenal-enhanced MMP-2 production in vascular smooth muscle cells," Athe- rosclerosis, vol. 208, no. 1, pp. 56-61, 2010.

[38] P. Libby, "Vascular biology of atherosclerosis: overview and state of the art," American Journal of Cardiology, vol. 91, no. 3, supplement, pp. 3-6, 2003.

[39] P. E. Szmitko, C.-H. Wang, R. D. Weisel, J. R. De Almeida, T. J. Anderson, and S. Verma, "New markers of inflammation and endothelial cell activation part I," Circulation, vol. 108, no. 16, pp. 1917-1923, 2003.

[40] P. M. Ridker, M. J. Stampfer, and N. Rifai, "Novel risk factors for systemic atherosclerosis: a comparison of C-reactive protein, fibrinogen, homocysteine, lipoprotein(a), and standard cholesterol screening as predictors of peripheral arterial disease," Journal of the American Medical Association, vol. 285, no. 19, pp. 2481-2485, 2001.

[41] G. Riccioni, A. Zanasi, N. Vitulano, B. Mancini, and N. D’Orazio, "Leukotrienes in atherosclerosis: new target insights and future therapy perspectives," Mediators of Inflammation, vol. 2009, Article ID 737282, 6 pages, 2009.

[42] J. H. Dwyer, H. Allayee, K. M. Dwyer et al., "Arachidonate 5-lipoxygenase promoter genotype, dietary arachidonic acid, and atherosclerosis," New England Journal of Medicine, vol. 350, no. 1, pp. 29-37, 2004.

[43] D. M. Iovannisci, E. J. Lammer, L. Steiner et al., "Association between a leukotriene $\mathrm{C}_{4}$ synthase gene promoter polymorphism and coronary artery calcium in young women: the 
Muscatine study," Arteriosclerosis, Thrombosis, and Vascular Biology, vol. 27, no. 2, pp. 394-399, 2007.

[44] M. Bäck, "Inhibitors of the 5-lipoxygenase pathway in atherosclerosis," Current Pharmaceutical Design, vol. 15, no. 27, pp. 3116-3132, 2009.

[45] M. Mehrabian, H. Allayee, J. Wong et al., "Identification of 5Lipoxygenase as a major gene contributing to atherosclerosis susceptibility in mice," Circulation Research, vol. 91, no. 2, pp. 120-126, 2002.

[46] R. Y. Cao, T. S. Amand, R. Gräbner, A. J. R. Habenicht, and C. D. Funk, "Genetic and pharmacological inhibition of the 5-lipoxygenase/leukotriene pathway in atherosclerotic lesion development in ApoE deficient mice," Atherosclerosis, vol. 203, no. 2, pp. 395-400, 2009.

[47] J. Jawien, M. Gajda, M. Rudling et al., "Inhibition of five lipoxygenase activating protein (FLAP) by MK-886 decreases atherosclerosis in apoE/LDLR-double knockout mice," European Journal of Clinical Investigation, vol. 36, no. 3, pp. 141146, 2006.

[48] G. Riccioni, M. Bäck, and V. Capra, "Leukotrienes and atherosclerosis," Current Drug Targets, vol. 11, no. 7, pp. 882-887, 2010.

[49] N. D. Kim and A. D. Luster, "Regulation of immune cells by eicosanoid receptors," TheScientificWorldJournal, vol. 7, pp. 1307-1328, 2007.

[50] J. Jawien and R. Korbut, "The current view on the role of leukotrienes in atherogenesis," Journal of Physiology and Pharmacology, vol. 61, no. 6, pp. 647-650, 2010.

[51] J. Moraes, J. Assreuy, C. Canetti, and C. Barja-Fidalgo, "Leukotriene $\mathrm{B}_{4}$ mediates vascular smooth muscle cell migration through $\alpha \mathrm{v} \beta 3$ integrin transactivation," Atherosclerosis, vol. 212, no. 2, pp. 406-413, 2010.

[52] K. Sakata, S. E. Dahlén, and M. Bäck, "The contractile action of leukotriene B4 in the guinea-pig lung involves a vascular component," British Journal of Pharmacology, vol. 141, no. 3, pp. 449-456, 2004.

[53] E. A. Heller, E. Liu, A. M. Tager et al., "Inhibition of atherogenesis in BLT1-deficient mice reveals a role for LTB4 and BLT1 in smooth muscle cell recruitment," Circulation, vol. 112, no. 4, pp. 578-586, 2005.

[54] R. J. Aiello, D. Brees, and O. L. Francone, "ABCA1-deficient mice: insights into the role of monocyte lipid efflux in $\mathrm{HDl}$ formation and inflammation," Arteriosclerosis, Thrombosis, and Vascular Biology, vol. 23, no. 6, pp. 972-980, 2003.

[55] R. J. Aiello, D. Brees, P. A. Bourassa et al., "Increased atherosclerosis in hyperlipidemic mice with inactivation of ABCA1 in macrophages," Arteriosclerosis, Thrombosis, and Vascular Biology, vol. 22, no. 4, pp. 630-637, 2002.

[56] K. Subbarao, V. R. Jala, S. Mathis et al., "Role of leukotriene $\mathrm{B}_{4}$ receptors in the development of atherosclerosis: potential mechanisms," Arteriosclerosis, Thrombosis, and Vascular Biology, vol. 24, no. 2, pp. 369-375, 2004.

[57] S. Allen, M. Dashwood, K. Morrison, and M. Yacoub, "Differential leukotriene constrictor responses in human atherosclerotic coronary arteries," Circulation, vol. 97, no. 24, pp. 24062413, 1998.

[58] E. Nagy, D. C. Andersson, K. Caidahl et al., "Upregulation of the 5-lipoxygenase pathway in human aortic valves correlates with severity of stenosis and leads to leukotriene-induced effects on valvular myofibroblasts," Circulation, vol. 123, no. 12, pp. 1316-1325, 2011.

[59] C. F. H. Mueller, K. Wassmann, J. D. Widder et al., "Multidrug resistance protein-1 affects oxidative stress, endothelial dysfunction, and atherogenesis via leukotriene $\mathrm{C}_{4}$ export," Circulation, vol. 117, no. 22, pp. 2912-2918, 2008.
[60] J. Jawien, M. Gajda, P. Wołkow, J. Zurańska, R. Olszanecki, and R. Korbut, "The effect of montelukast on atherogenesis in apoE/LDLR — double knockout mice," Journal of Physiology and Pharmacology, vol. 59, no. 3, pp. 633-639, 2008.

[61] Y. Kaetsu, Y. Yamamoto, S. Sugihara et al., "Role of cysteinyl leukotrienes in the proliferation and the migration of murine vascular smooth muscle cells in vivo and in vitro," Cardiovascular Research, vol. 76, no. 1, pp. 160-166, 2007.

[62] D. Piomelli, S. J. Feinmark, and P. J. Cannon, "Leukotriene biosynthesis by canine and human coronary arteries," Journal of Pharmacology and Experimental Therapeutics, vol. 241, no. 3, pp. 763-770, 1987.

[63] R. De Caterina, A. Mazzone, D. Giannessi et al., "Leukotriene $\mathrm{B}_{4}$ production in human atherosclerotic plaques," Biomedica Biochimica Acta, vol. 47, no. 10-11, pp. S182-S185, 1988.

[64] D. A. Brezinski, R. W. Nesto, and C. N. Serhan, "Angioplasty triggers intracoronary leukotrienes and lipoxin A4: impact of aspirin therapy," Circulation, vol. 86, no. 1, pp. 56-63, 1992.

[65] A. Helgadottir, A. Manolescu, G. Thorleifsson et al., "The gene encoding 5-lipoxygenase activating protein confers risk of myocardial infarction and stroke," Nature Genetics, vol. 36, no. 3, pp. 233-239, 2004.

[66] B. Lefebvre, J. L. Pépin, J. P. Baguet et al., "Leukotriene $\mathrm{B}_{4}$ : early mediator of atherosclerosis in obstructive sleep apnoea?" European Respiratory Journal, vol. 32, no. 1, pp. 113-120, 2008.

[67] F. Stanke-Labesque, M. Bäck, B. Lefebvre et al., "Increased urinary leukotriene $\mathrm{E}_{4}$ excretion in obstructive sleep apnea: effects of obesity and hypoxia," Journal of Allergy and Clinical Immunology, vol. 124, no. 2, pp. 364-370.e2, 2009.

[68] M. Bäck, H. Hlawaty, C. Labat, J. B. Michel, and C. Brink, "The oral cavity and age: a site of chronic inflammation?” PLoS One, vol. 2, no. 12, Article ID e1351, 2007.

[69] M. Bäck, S. Airila-Månsson, T. Jogestrand, B. Söder, and P. O. Söder, "Increased leukotriene concentrations in gingival crevicular fluid from subjects with periodontal disease and atherosclerosis," Atherosclerosis, vol. 193, no. 2, pp. 389-394, 2007.

[70] H. Hakonarson, S. Thorvaldsson, A. Helgadottir et al., "Effects of a 5-lipoxygenase-activating protein inhibitor on biomarkers associated with risk of myocardial infarction: a randomized trial," Journal of the American Medical Association, vol. 293, no. 18, pp. 2245-2256, 2005.

[71] H. Allayee, J. Hartiala, W. Lee et al., "The effect of montelukast and low-dose theophylline on cardiovascular disease risk factors in asthmatics," Chest, vol. 132, no. 3, pp. 868-874, 2007.

[72] J. C. Tardif, P. L. L'Allier, R. Ibrahim et al., "Treatment with 5lipoxygenase inhibitor VIA-2291 (atreleuton) in patients with recent acute coronary syndrome," Circulation: Cardiovascular Imaging, vol. 3, no. 3, pp. 298-307, 2010.

[73] E. Ingelsson, L. Yin, and M. Bäck, "Nationwide cohort study of the leukotriene receptor antagonist montelukast and incident or recurrent cardiovascular disease," Journal of Allergy and Clinical Immunology. In press.

[74] V. Capra, M. Ambrosio, G. Riccioni, and G. E. Rovati, "Cysteinyl-leukotriene receptor antagonists: present situation and future opportunities," Current Medicinal Chemistry, vol. 13, no. 26, pp. 3213-3226, 2006.

[75] G. Riccioni, V. Capra, N. D’Orazio, T. Bucciarelli, and L. A. Bazzano, "Leukotriene modifiers in the treatment of cardiovascular diseases," Journal of Leukocyte Biology, vol. 84, no. 6, pp. 1374-1378, 2008. 


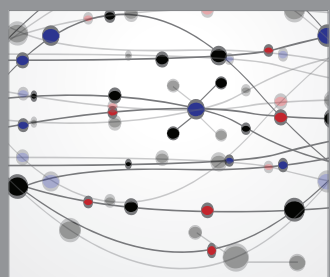

The Scientific World Journal
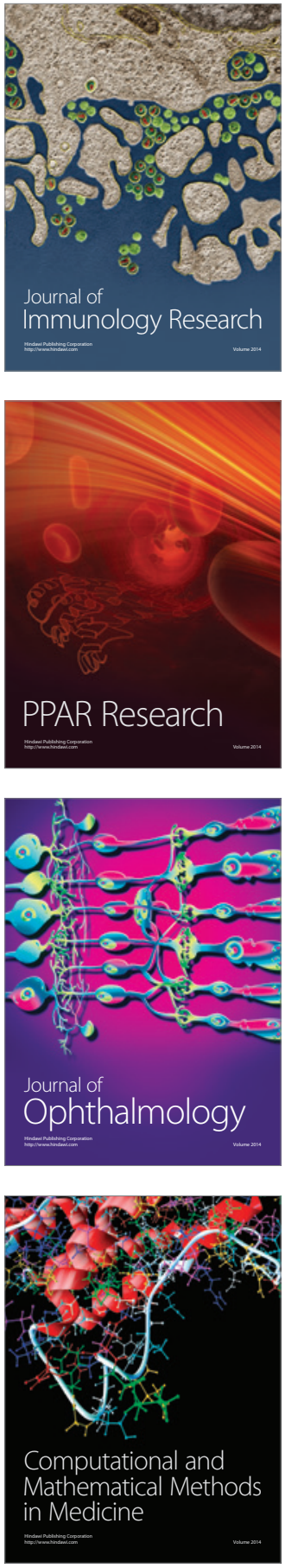

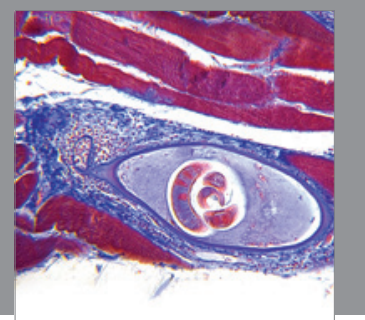

Gastroenterology

Research and Practice
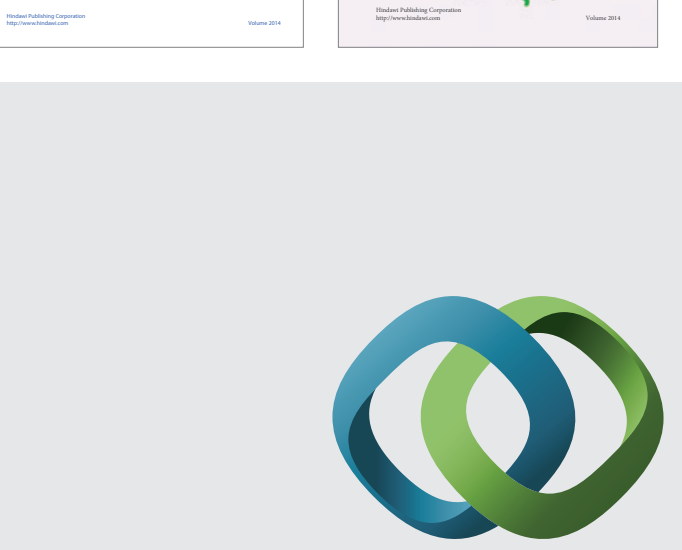

\section{Hindawi}

Submit your manuscripts at

http://www.hindawi.com
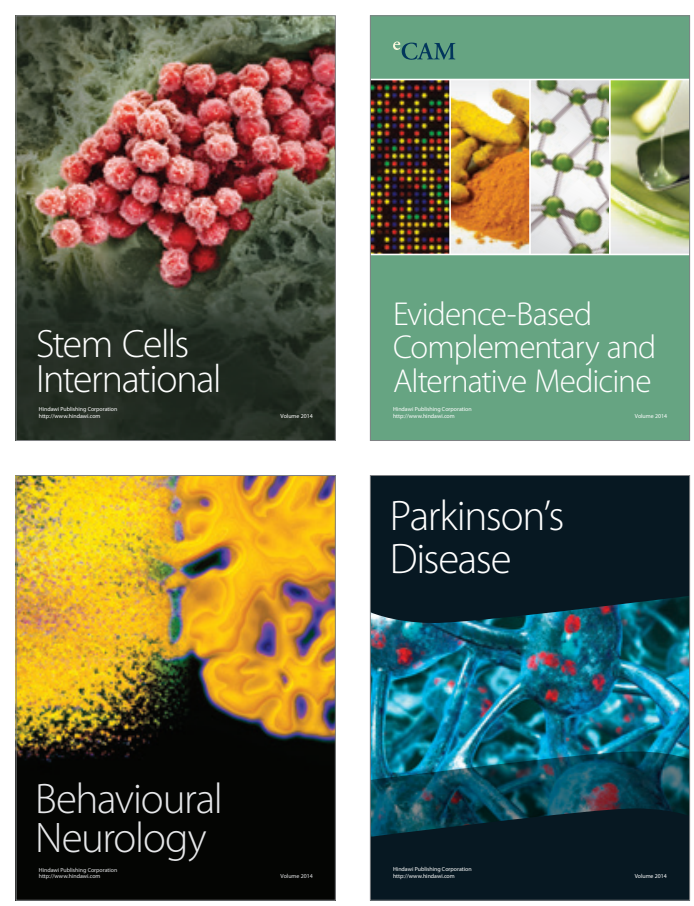

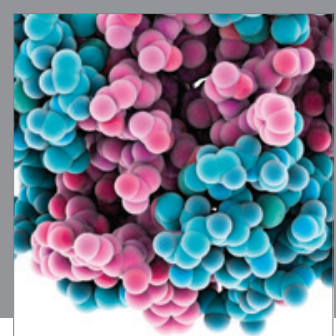

Journal of
Diabetes Research

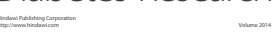

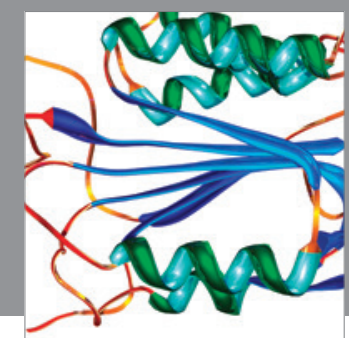

Disease Markers
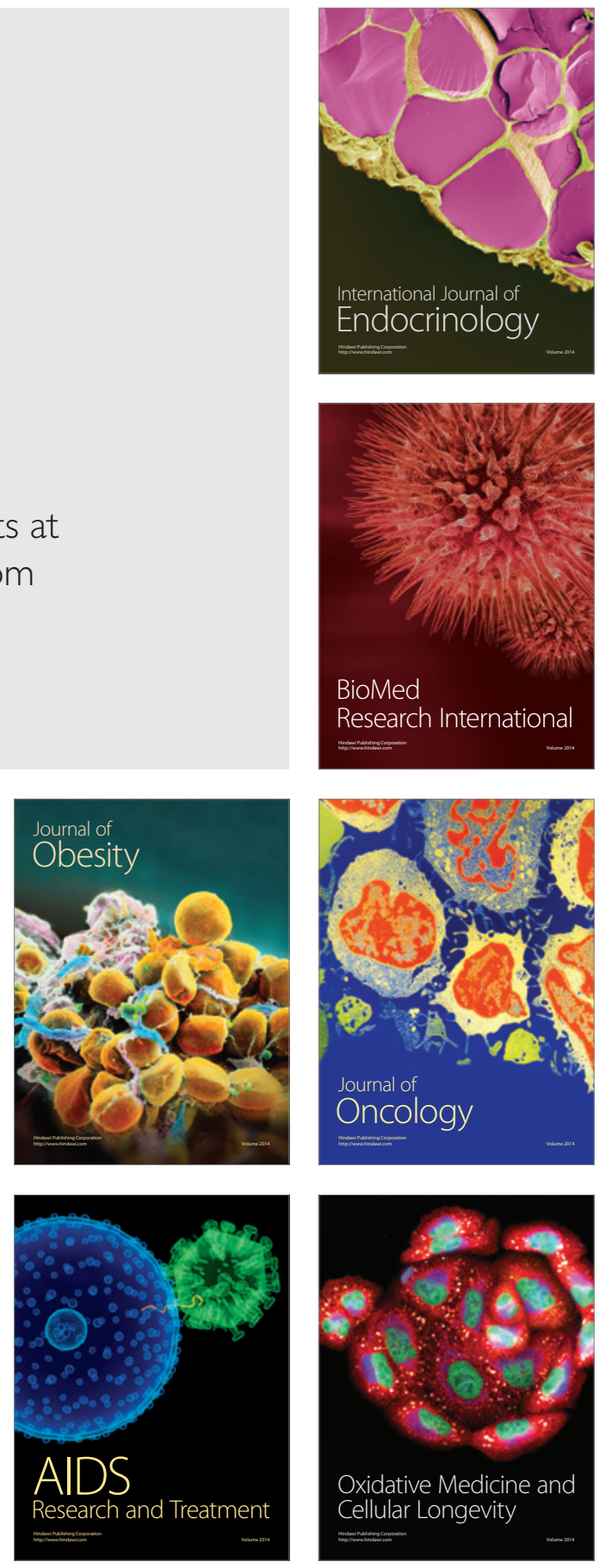